\title{
Investigation and isolation of the active constituents of petroleum ether fraction of Medicago sativa L. sprouts
}

\author{
Ahmed A. Seida ${ }^{1,2}$, Hala El-Hefnawy ${ }^{1}$, Dina R. Abou-Hussein ${ }^{1,3},{ }^{*}$ Fatma Alzahraa Mokhtar ${ }^{1}$ \\ ${ }^{1}$ Pharmacognosy Department, Faculty of Pharmacy, Cairo University, Cairo, Egypt \\ ${ }^{2}$ President, October 6 University, Giza, Egypt \\ ${ }^{3}$ Department of Natural Products and Alternative Medicine, Faculty of Pharmacy, King Abdul aziz University, Jeddah 21589, Saudi Arabia
}

\begin{abstract}
The unsaponifiable fraction from petroleum ether extract of Medicago sativa L. sprouts was analyzed by GLC, a series of 17 hydrocarbons and 2 phytosterols; $\beta$-sitosterol and stigmasterol were identified. Analysis of the fatty acid fraction by GLC techniques revealed the presence of 6 saturated fatty acids and 8 unsaturated fatty acids including omega 6 - fatty acid lionleic acid and 2 omega 3 fatty acids Eicosapentaenoic acid (EPA) and Docosahexaenoic acid (DHA) in a relative percent of $1.0 \%$ and $1.12 \%$, respectively. These two types are rarely produced in plants but produced in fish, which have protective effects against heart diseases, liver functions and inflammations.
\end{abstract}

Key Words: Medicago, omega- 3, stigmasterol, $\beta$-sitosterol.

\section{INTRODUCTION}

The genus Medicago (Family: Fabaceae) comprises over 85 species of annual or perennial herbs rarely shrubs (Hutchinson, 1961), Medicago species are distributed in the temperate regions; in the Mediterranean region, west and central Asia, North America, Ethiopia and southern Africa (Boulos, 1999). In Egypt, the genus Medicago is represented by 18 wild species, from which only Medicago sativa $\mathrm{L}$. is cultivated and may be found wild as escape from cultivation (Boulos, 1999) M. sativa is a common forage plant present all the year. Nowadays $M$. sativa sprouts is added to salad menus in several European countriesas a healthy food but no data are available for the sprouts composition and fractions so, this study was designed to determine the chemical composition of the petroleum ether fraction of M. sativa sprouts.

\section{MATERIALS AND METHODS}

\section{Plant material}

Aerial parts and Seeds of Medicago sativa L. were collected late in June from fully mature plant cultivated in keram farms, ModerayatAltahrir, Behaira, Egypt. The identity of the plant was kindly confirmed by Prof. Dr. Abdel Megeed Ali Abdel Megeed, Prof. of Plant Taxonomy, Flora and Phytotaxonomy Researches Department, Horticultural Researches Institute, Agricultural Research Center, Dokki, Cairo, Egypt. The seeds were sprouted as follows: dry seeds weight of $4.5 \mathrm{~kg}$ were soaked in water for 18 hours then drained off soaking water, rinsed thoroughly every $12 \mathrm{~h}$ for 6 days till fresh sprouts lengthen 7-12 cm with green leaflets. Finally, the sprouts were shadow dried resulted in $4.3 \mathrm{~kg}$ dry sprouts.

\begin{abstract}
Chromatography
Silica gel 60, particle size (0.063-0.2), 70-230 mesh, (EMerck, Darmstadt, Germany) was used for column chromatography. Pre-coated silica gel 60 on aluminum sheets, $0.2 \mathrm{~mm}$ thickness, 20x20cm (E-Merck, Darmstadt, Germany) was used for TLC. Solvent systems included hexane: ethyl acetate in different ratios for column chromatography and hexane:ethyl acetate (80:20) for TLC. Anisaldehyde spray and UV light at a wavelength of 365 $\mathrm{nm}$ was used for visualization. Apparatus used: Rotatory evaporator (Eyela Co., Japan), Centrifuge; Jouan centrifuge 1,000-10,000 rpm, France, Spectrophotometer STATFAX 3300 (Florida, USA). For serum glucose and serum lipid measurements, Mass spectrometer; SSQ 7000 (Finnigan), NRC, Giza, Cairo was used. GLC analysis was carried out according to the following conditions mentioned by Vogel (1975) and A.O.A.C (2000).
\end{abstract}

\section{Conditions for (unsaponified matter) USM}

Thermo TR-5MS column, coated with 3\% OV-17, Column dimensions $2.8 \mathrm{~m} \times 0.25$ inch i.d, oven temperature $70^{\circ} \mathrm{C}$ temperature programming $70^{\circ} \mathrm{C}$ for $2 \mathrm{~min}$., increased to $270^{\circ} \mathrm{C}$ by the rate of $10^{\circ} \mathrm{C} / \mathrm{min}$., then isothermally for 25 min. carrier gas nitrogen, flow rate $30 \mathrm{ml} / \mathrm{min}$, sample size $2 \mu \mathrm{l}$, injector temperature $230^{\circ} \mathrm{C}$, detector temperature $280^{\circ} \mathrm{C}$.

\section{Conditions for (fatty acids) FA}

Thermo TR-FAME column, coated with $10 \%$ polyethylene glycol adipate (PEGA), column dimensions $2.8 \mathrm{~m} \times 0.25$ inch i.d, oven temperature $70^{\circ} \mathrm{C}$ for $2 \mathrm{~min}$., increased to $190^{\circ} \mathrm{C}$ by the rate of $8^{\circ} \mathrm{C} / \mathrm{min}$., then isothermally for 25 min, carrier gas nitrogen, flow rate $30 \mathrm{ml} / \mathrm{min}$, sample size $2 \mu \mathrm{l}$, injector temperature $200^{\circ} \mathrm{C}$, detector temperature $220^{\circ} \mathrm{C}$.

\section{Extraction and isolation}

The dry sprouts were extracted with $70 \%$ methanol by successive percolation $(10 \times 8 \mathrm{~L})$ and concentrated under vaccum using rotary evaporator at $45^{\circ} \mathrm{C}$ to yield $900 \mathrm{~g}$ residue. A weight of $500 \mathrm{~g}$ of the dry alcoholic extract of the 


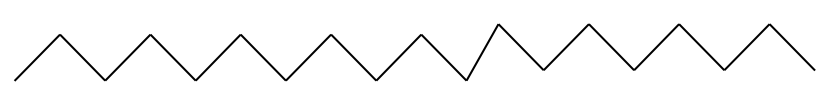

(A)

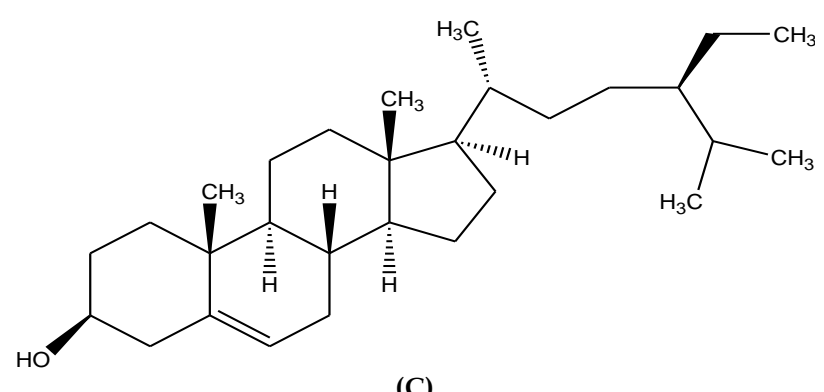

(C)

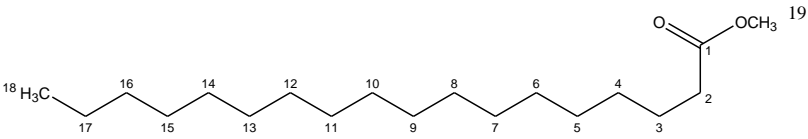

(B)

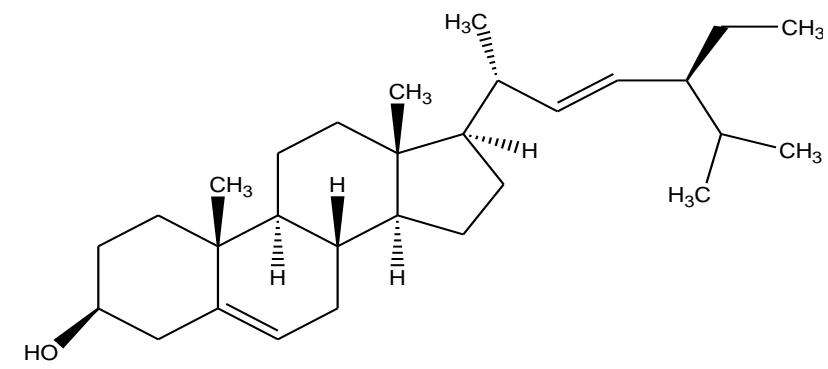

(D)

Figure 1: Isolated compounds of petroleum ether fraction of $M$. sativa sprouts: (A) n-nonadecane, (B) methyl stearate, (C) $\beta$-sitosterol, (D) stigmasterol.

sprouts of Medicago sativa L. was suspended in least amount of water partitioned with petroleum ether fraction yielded $32.5 \mathrm{~g}(6.5 \%)$, about $1 \mathrm{~g}$ of the pet. ether extract was saponified $(\mathrm{N} / 2 \mathrm{KOH})$ and the unsaponified matter was separated. The liberated fatty acid mixture was extracted, methylated (methanol, $4.5 \%$ HCL). Samples of the unsaponifiable fraction and the fatty acids were subjected to GLC analysis. Petroleum ether extract (30g) was loaded on a silica gel column $(8 \times 140 \mathrm{~cm}, 800 \mathrm{~g})$, use mobile phase of hexane: ethyl acetate 0:100 up to 100:0 formed 88 fractions each of $250 \mathrm{ml}$ which were monitored by TLC, using the solvent system hexane : ethyl acetate $(80: 20)$ the chromatograms were examined in visible and UV light at (365 and $254 \mathrm{~nm}$ ) and sprayed with $p$ anisaldehyde reagent, similar fractions were pooled together and the solvents were separately evaporated under reduced pressure yielded 11 major fractions.

Fraction (2), eluted by $85 \%$ of hexane:ethylacetate, rechromatographed on silica gel column, use hexane:ethyl

Table 1: Results of GLC analysis of the fatty acids methyl esters of saponifiable fractions of the $n$-hexane extracts of the sprouts of M. sativa.

\begin{tabular}{|c|c|c|}
\hline Identified compounds & RRT $^{*}$ & Relative\% \\
\hline Decanoic (Capric) acid C10:0 & 0.486 & 1.34 \\
\hline Dodecanoic (Lauric) acid C12:0 & 0.55 & 1.42 \\
\hline Tetradecanoic (Myristic) acid C14:0 & 0.724 & 0.67 \\
\hline Hexadecanoic (Palmitic) acid C16:0 & 0.941 & 12.751 \\
\hline Hexadecanoic (Palmitoleic) acid C16:1 & 1 & 27.58 \\
\hline Octadecanoic (Stearic) acid C18:0 & 1.39 & 3.792 \\
\hline Octadecenoic (Oleic) acid C18:1 & 1.084 & 8.64 \\
\hline Octadecadienoic (Linoleic) acid C18:2 & 1.66 & 26.85 \\
\hline Octadecadienoic (Linoelaidic) acid C18:2 & 1.89 & 12.071 \\
\hline Octadecatrienoic (Lionleic) acid 18:3 & 2.31 & 0.53 \\
\hline Eicosanoic (Arachidic) acid 20:0 & 2.6 & 1.591 \\
\hline Eicosatetrienoic (Archidonic) acid 20:4 & 3.25 & 0.65 \\
\hline Eicosapentaenoic acid (EPA) & 3.72 & 1 \\
\hline Docosahexaenoic acid (DHA) & 4.545 & 1.12 \\
\hline \multicolumn{2}{|c|}{ Percentage of identified saturated fatty acids } & s $\quad 21.571$ \\
\hline \multicolumn{2}{|c|}{ Percentage of identified unsaturated fatty acids } & s 78.429 \\
\hline
\end{tabular}

acetate $(90-85 \%)$ showed compound $\mathrm{T}_{1}$ and compound $\mathrm{T}_{2}$.

Fraction [4], eluted by $70 \%$ of hexane:ethyl acetate, use hexane:ethyl acetate $(85-70 \%)$ showed the presence of compound $\mathrm{T}_{3}$.

Fraction [5], (420 mg): eluted by $70 \%$ of hexane:ethyl acetate showed the presence compound $\mathrm{T}_{4}$.

These compounds were identified by spectroscopic methods (MS) and determined against reference standard compounds.

\section{RESULTS AND DISCUSSION}

GLC analysis of fatty acids of $M$. sativa sprouts showed the presence of 14 compounds which were identified. The identified saturated and unsaturated fatty acids were found to represent 21.1 and 76.3 relative \% of $\mathrm{FA}$,

Table 2: Results of GLC analysis of the unsaponifiable fractions of the $n$-hexane extracts of the sprouts of $M$. sativa.

\begin{tabular}{|c|c|c|c|}
\hline \multicolumn{2}{|c|}{ Peak No. Identified Compounds } & \multirow{2}{*}{$\frac{\text { RRT }^{* *}}{0.492}$} & \multirow{2}{*}{$\begin{array}{c}\text { Relative \% } \\
1.69\end{array}$} \\
\hline 1 & Tetradecane & & \\
\hline 2 & Pentadecane & 0.506 & 0.726 \\
\hline 3 & Hexadecane & 0.53 & 1.01 \\
\hline 4 & Heptadecane & 0.549 & 0.322 \\
\hline 5 & Octadecane & 0.555 & 1.613 \\
\hline 6 & Nonadecane & 0.601 & 0.848 \\
\hline 7 & Eicosane & 0.607 & 10.01 \\
\hline 8 & Heneicosane & 0.637 & 0.906 \\
\hline 9 & Docosane & 0.679 & 5.277 \\
\hline 10 & Tricosane & 0.736 & 1.487 \\
\hline 11 & Tetracosane & 0.753 & 13.254 \\
\hline 12 & Hexacosane & 0.804 & 8.29 \\
\hline 13 & Heptacosane & 0.878 & 1.539 \\
\hline 14 & Octacosane & 0.935 & 3.864 \\
\hline 15 & Nonacosane & 0.949 & 0.941 \\
\hline 16 & Stigmasterol & 1 & 18.526 \\
\hline 17 & $\beta$-Sitosterol & 1.009 & 9.851 \\
\hline 18 & Triacontane & 1.017 & 5.203 \\
\hline \multirow[t]{3}{*}{19} & Dotriacontane & 1.023 & 14.54 \\
\hline & \multicolumn{2}{|c|}{ Percentage of total hydrocarbons } & 71.62 \\
\hline & \multicolumn{2}{|c|}{ Percentage of total sterols } & 28.38 \\
\hline
\end{tabular}

RRT $^{* *}$ : Relative retention time to stigmasterol ( $\left.\mathrm{R}_{\mathrm{t}}=44.2 \mathrm{~min}\right)$ 
respectively. Palmitic acid (12.75\%) was found to be the major saturated FA, followed by arachidic acid (1.59\%), while palmitoleic acid (27.28\%) was found to be the major unsaturated FA, followed by linoleic acid (26.85\%) and linoelaidic acid $(12.07 \%)$. The plant contains two types of Omega-3 fatty acids docosahexanoic acid (DHA) (1.12\%) and Eicosapentaenoic acid (EPA) $(1.0 \%)$ as illustrated in table 1. GLC analysis of USM of M. sativa sprouts revealed the presence of 19 compounds which were identified. The identified hydrocarbons and sterols were found to represent 71.62 and 28.38 relative \% of USM, respectively. n-dotriacontane (14.54 relative \%) was found to be the major hydrocarbon, followed by n-tetracosane (13.254 relative \%), while stigmasterol (18.526 relative \%) was found to be the major sterol in USM, followed by $\beta$ sitosterol (9.851 relative \%). Stigmasterol and compactin were the most isolated sterol compounds from the plant (Shingoet al., 1987) and (Huang and Grunwald, 1988) while omega 3 fatty acids were not reported before although they are detected in this research in a reasonable amounts (2.12) relative \% of fatty acid methyl esters as illustrated in table 2.

\section{Compound 1}

The mass spectrum of compound $\mathrm{T}_{1}$ showed molecular ion peak at 268, $267 \mathrm{~m} / \mathrm{z}$ and other ion at $\mathrm{m} / \mathrm{z}=253$ represented the loss of $\mathrm{CH}_{2}$ group and other peak at $\mathrm{m} / \mathrm{z}=$ 239 represented the loss of other $\mathrm{CH}_{2}$ group. The molecular formula was estimated as $\mathrm{C}_{19} \mathrm{H}_{40}$. These data resembled that of a simple aliphatic hydrocarbon n-nonadecane (Guillaume et al., 2003).

\section{Compound 2}

The mass spectrum of compound $\mathrm{T}_{1}$ showed molecular ion peak at 299, $298 \mathrm{~m} / \mathrm{z}$ and other ion at $\mathrm{m} / \mathrm{z}=269$ represented the loss of two methyl group and other peak at $\mathrm{m} / \mathrm{z}=255$. The molecular formula was estimated as $\mathrm{C}_{19} \mathrm{H}_{38} \mathrm{O}_{2}$, The data of this compound resemble the published data of the methyl stearate (fatty acid methyl ester) (Biemann, 1962).

\section{Compound 3}

separated as yellowish white powder, Mass spectrum, showed a molecular ion peak of $414 \mathrm{~m} / \mathrm{z}\left(\mathrm{C}_{29} \mathrm{H}_{50} \mathrm{O}\right) ; 396$ $\left(\mathrm{M}^{+}-\mathrm{H}_{2} \mathrm{O}\right), 255\left(\mathrm{M}^{+}\right.$- side chain) and peak at $\mathrm{m} / \mathrm{z} 145$ $(18.5 \%)$ was due to fragmentation of sitosterol side chain with addition of two protons. The mass spectra of this compound were consistent with those published previously for $\beta$-sitosterol (Kamboj and Saluja, 2011).

\section{Compound 4}

Separated as white powder, mass spectrum showed a molecular ion peak of $411 \mathrm{~m} / \mathrm{z}[\mathrm{M}-\mathrm{H}],\left[\left(\mathrm{C}_{29} \mathrm{H}_{50} \mathrm{O}\right)-\mathrm{H}\right] ; 383$ $\left(\mathrm{M}-\mathrm{H}-\mathrm{H}_{2} \mathrm{O}\right), 351 \mathrm{~m} / \mathrm{z}$ resulted from the loss of methyl group, $255\left(\mathrm{M}^{+}\right.$- side chain) and peak at $\mathrm{m} / \mathrm{z} 145(18.5 \%)$ was due to fragmentation of sitosterol side chain with addition of two protons. The mass spectra of this compound were consistent with those published previously for stigmasterol (Kamboj and Saluja, 2011).

\section{CONCLUSION}

Petroleum ether fraction of Medicago sativa sprouts is a rich source of plant sterols, omega 3 fatty acids and omega 6 fatty acids like fish oils with much greater availability, so further biological studies should be performed to detect its preventive effects on atherosclerosis and heart diseases.

\section{ACKNOWLEDGEMENT}

The greatest support to this study came from Professor Mokhtar Ali Mohammed Aldosoky who encourage this study and supported this scientific research.

\section{REFERENCES}

A.O.A.C (2000) Official Methods of Analysis of the Association of Official Analytical Chemist, $14^{\text {th }}$ ed., Washington D.C.

Biemann, K, (1962)."Mass Spectrometry: Organic Chemical Applications," McGraw-Hill, New York.

Boulos, L. (1999) Flora of Egypt. Alhadara Publishing, Cairo, 1, 249-276.

Guillaume, F., Ryckaert, J. P., Rodriguez, V.; Mac Dowell, L.G., Girard, P. and Dianoux, A.J. (2003) Molecular dynamics in solid n-nonadecane: experiments and computer simulations. J. Phase transitions, 76, 823830.[DOI]

Huang, L. and Grunwald, C. (1988)Effect of light on sterol changes in Medicago sativa, J. Plant Physiology, 88, 1403-1406.[DOI]

Hutchinson, J. (1961) The families of flowering plants, The Clarendon Press, Oxoford, 3 ${ }^{\text {ed }}$ Ed., Part I, 189-196.

Kamboj, A. and Saluja, A.K. (2011) Isolation of stigmasterol and $\beta$ sitosterol from petroleum ether extract of aerial parts of ageratum conyzoides (Asteraceae). Inter. J. Phar. Pharm. Sci, 3(1), 94-96.

Shingo, H.,Tacagishi, H. and Koushi, H.(1987) Variation in the content and composition of sterols in alfalfa seedlings treated with compactin (ML236B) and mevalonic acid, J. P. Cell. Physio.,28(4), 709-714.

Vogel, AI. (1975) Practical Organic Chemistry, 3rd Ed., 969-971. English Language Book Society and Longman Group Ltd., London. 